\title{
Pesticide and its Risk Assessment
}

\author{
Pritam Ganguly ${ }^{1 *}$, Vinod Kumar Singh ${ }^{2}$ \\ ${ }^{1}$ Department of Soil Science \& Agricultural Chemistry, Bihar Agricultural University, India \\ ${ }^{2}$ Department of Plant Breeding and Genetics, Bihar Agricultural University, India
}

Submission: December 05, 2017; Published: January 18, 2018

*Corresponding author: Pritam Ganguly, Department of Soil Science \& Agricultural Chemistry, Bihar Agricultural University, India, Tel: 09051553500; Email: pritam0410@gmail.com

Abstract

Use of chemical pesticides is often being considered as the cause of health hazards to human. Effects of pesticide may be short-term or long term depending upon the exposure which results into acute and chronic toxicity respectively. Risk of pesticide injury depends upon both toxicity and exposure and can be lowered down by avoiding such exposure. Pesticide contamination in food and drinking water is quite observed and thus, dietary risk assessment of any pesticide needs to be determined. For assessment of risk, processes have to be followed to determine permissible intake of the pesticide. By comparing this data with residual contribution of that particular pesticide, safety assessment can be judged. However, multi-residue exposure of pesticides needs to be determined critically in future.

Keywords: Pesticide; Toxicity; Poisoning; Exposure; Risk assessment

\section{Introduction}

Pesticides are indispensible input in modern agriculture. They may be synthesized in chemical laboratory as xenobiotics or can be derived from natural sources of plant or microbial origin. Bio control agents, useful tool in pest management, are also being categorically considered as bio-pesticide. Among these, chemical pesticides are of major concern as they have the potency to cause health hazard in human. They are applied in the field to control major pests of crops, leaving toxic residues in environment. Although, pesticides do benefit the crops; but they impose a serious threat to the ecosystem [1]. The situation gets worsen when these compounds undergo bioaccumulation and enter into food chain. Majority of chemical pesticides are lipophilic in nature and hence, used to be absorbed in human fat.

\section{Route of exposure}

Started from mixing and applying in the field to consumption of produce, in each step even in routine use, pesticide can cause poisoning. These can be carried away from the site of application through different agents like wind, water, animals etc., and deposited to the non-target area. There could be occupational exposure as found in case of applicator in field, household, greenhouses or worker in industry, sales houses etc. It is evident that who are involved in mixing, loading, transport and application of pesticide are at highest risk of pesticide injury [2]. Apart from that, there are some occurrences of accidental spillage, leakage and faulty applications.

Pesticides can enter into human body in three ways:
a. Through mouth (oral administration),
b. By adsorption through skin or eyes (dermal adsorption) and

c. By breathing (inhalation) [3].

\section{Factors that mainly affect pesticide exposure}

a) Extent of exposure may depend on pesticide formulation. Liquids are prone to leakage and splashing while solid dusts are subjected to drift.

b) Type of packaging.

c) Weather condition at the time of spray or application.

d) Efficiency of applicator.

\section{Pesticide toxicity}

Human beings are mostly exposed to pesticides through contaminated food and drinking water. These phenomenons are mainly occurred through non-occupational exposure and leads to low dose-chronic (or semi-chronic) toxicity [4]. However, occupational exposure often leads to acute toxicity which is considered to be more dangerous and found to be lethal at the same time. Symptoms of pesticide poisoning are often misleading. There are some common symptoms observed in case of pesticide poisoning such as nausea, headache, abdominal pain, vomiting tendency, fatigue, loss of appetite, blurred vision etc. But, these symptoms are often confused with general illness which needs medical attention. 


\section{Risk assessment}

Risk related to pesticide poisoning can be defined as the extent of getting exposed to a pesticide with certain degree of toxicity. These can be expressed as:

\section{Risk = Toxicity X Exposure [3]}

Avoidance of exposure can definitely lower down the level of risk that associated with the use of potentially toxic pesticides. Toxicity of any pesticide cannot be altered but risk can be managed. Dietary risk assessment of any pesticide is a critical study in which several processes are involved. Toxicological tests involving animal laboratory animal are carried out to calculate Acceptable Daily Intake (ADI) value of a particular pesticide. At the same time, multi-locational field trials have to be conducted to find out the residual fate of that pesticide at recommended dose in a crop. From that experiment, Theoretical Maximum Residue Contribution (TMRC) of that pesticide can be determined by multiplying daily consumption of the harvest product with amount of pesticide residue found [5]. Moreover, one has to calculate Maximum Permissible Intake (MPI) of that pesticide for humans by multiplying ADI with average body weight. Finally, TMRC value has to be compared with MPI value and if found less than the later, the pesticide may be considered as safe to consume.

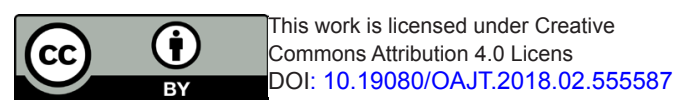

\section{Advance research}

Non-occupational low dose exposure of any pesticide causes chronic diseases in humans and can be considered as silent killer. But, almost every crop in its life span faces number of applications of different pesticide which results into multiresidue exposure of those pesticides to human being. Effect of multi-residue exposure could be more dangerous if any synergistic effects are being observed in causing toxicity effects. Thus, studies have to be performed to evaluate the effects of multi-residues of pesticides in human.

\section{References}

1. Mahmood I, Imadi SR, Shazadi K, Gul A, Hakeem KR (2016) Effects of Pesticides on Environment. Plant, Soil and Microbes pp. 253-269.

2. Fenske RA, Day EW (2005) Assessment of exposure for pesticide handlers in agricultural, residential and institutional environments. Occupational and residential exposure assessment for pesticides $\mathrm{p}$. 11-43.

3. Schulze LD, Ogg C, Vitzthum EF (1997) EC97-2505 Signs and Symptoms of Pesticide Poisoning.

4. Damalas CA, Eleftherohorinos IG (2011) Pesticide exposure, safety issues, and risk assessment indicators. Int J Environ Res Public Health 8(5): 1402-1419.

5. Paramasivam M, Selvi C, Chandrasekaran S (2014) Persistence and dissipation of flubendiamide and its risk assessment on gherkin (Cucumis anguria L.). Environ Monit Assess 186(8): 4881-4887.

\section{Your next submission with Juniper Publishers will reach you the below assets}

- Quality Editorial service

- Swift Peer Review

- Reprints availability

- E-prints Service

- Manuscript Podcast for convenient understanding

- Global attainment for your research

- Manuscript accessibility in different formats

( Pdf, E-pub, Full Text, Audio)

- Unceasing customer service

Track the below URL for one-step submission

https://juniperpublishers.com/online-submission.php 